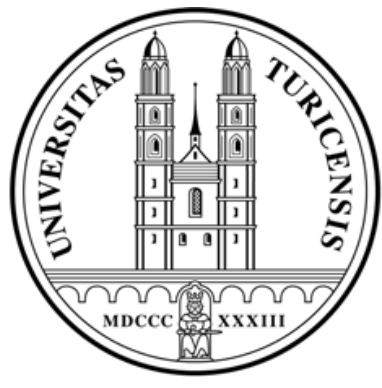

Institute for Empirical Research in Economics

University of Zurich

Working Paper Series

ISSN 1424-0459

Working Paper No. 200

Why the Olympics have three prizes and not just one

Pavlo Blavatskyy

August 2004 


\title{
Why the Olympics have three prizes and not just one Pavlo Blavatskyy*
}

\author{
Institute for Empirical Research in Economics \\ University of Zurich \\ Winterthurerstrasse 30 \\ CH-8006 Zurich \\ Switzerland \\ Phone: +41(1)6343586 \\ Fax: +41(1)6344978 \\ e-mail: pavlo.blavatskyy@iew.unizh.ch
}

August 2004

\begin{abstract}
:
There are at least two reasons why multiple prizes can be optimal in symmetric imperfectly discriminating contests. First, the introduction of multiple prizes reduces the standard deviation of contestants' effort in asymmetric equilibria, when the majority of contestants actively participate in competition. Second, the introduction of multiple prizes may increase the aggregate (average) effort contributed in the contest. When more of a total prize fund is shifted away from the first prize, on the one hand, the active contestants obtain an incentive to reduce their individual effort, but, on the other hand, the number of active contestants may increase. Therefore, the aggregate (average) effort may increase when the number of active contestants in equilibrium increases.
\end{abstract}

Keywords: symmetric contest, imperfectly discriminating contest, logit, asymmetric equilibria, prize structure, sport

\section{JEL Classification codes: C72, L13, L83}

\footnotetext{
* I am grateful to Avner Shaked, Andreas Ortmann, Dirk Engelmann and Stepan Jurajda for helpful comments. This paper was written while I was on a study stay at the School of Economics, University of Nottingham, whose hospitality is acknowledged.
} 


\section{Why the Olympics have three prizes and not just one}

\section{Introduction}

In imperfectly discriminating contests the contestants contribute effort to win prize(s) and the highest effort does not necessarily secure a win (e.g. Dixit, 1987). Such contests are typical inter alia in sport (e.g. Neale, 1964). The existing literature largely concentrates on the single prize contests (e.g. Nitzan, 1994, p.52) despite overwhelming evidence that multiple prizes are awarded in real-life contests (e.g. Moldovanu and Sela, 2002, Szymanski, 2003, p.1142). Clark and Riis (1998, pp. 616-617) and Szymanski (2003, pp. 1142-1143) concluded that a single prize is always optimal in symmetric imperfectly discriminating contests. However, this result is only derived from an analysis of the symmetric Cournot-Nash equilibrium. Moldovanu and Sela (2001) demonstrated that multiple prizes can be optimal in perfectly discriminating contests if the cost of effort is sufficiently convex. Szymanski and Valletti (2002) demonstrated that multiple prizes can be optimal in asymmetric imperfectly discriminating contests when the contestants are sufficiently different in ability.

In symmetric imperfectly discriminating contests there may exist either a symmetric Cournot-Nash equilibrium or asymmetric equilibria (e.g. Cornes and Hartley, 2003). PerezCastrillo and Verdier (1992) demonstrated that the classical Tullock (1980) contest has a symmetric Nash equilibrium, asymmetric Nash equilibria, or a Stackelberg equilibrium. In this paper, I introduce multiple prizes into the Tullock (1980) contest in the same way as Clark and Riis (1998, pp.608-609) and Szymanski (2003, p.1142). The complete structure of equilibria is analyzed, including the asymmetric equilibria ignored in Clark and Riis (1998) and Szymanski (2003, p.1142, footnote 16). When the asymmetric equilibria are taken into account, a single 
prize is not necessarily the optimal prize structure for symmetric imperfectly discriminating contests.

The remainder of this paper is structured as follows. The complete structure of equilibria in the Tullock (1980) contest with a single prize is presented in section 2. Section 2 mainly restates the results from Perez-Castrillo and Verdier (1992). Additionally, I argue that the Stackelberg equilibrium arises endogenously for the parameterization incompatible with the existence of a pure strategy Nash equilibrium. In Section 3, I analyze the Tullock (1980) contest with two prizes (e.g. Szymanski, 2003, p. 1142) and demonstrate that the second prize may be optimal. Section 4 concludes.

\section{Tullock (1980) contest with a single prize}

Consider $n \geq 2$ identical contestants for a single prize $V>0$. Each contestant contributes an effort $e_{i} \geq 0, i \in[1, n]$, and has a probability $p\left(e_{i}\right)=e_{i}^{r} / \sum_{j=1}^{n} e_{j}^{r}$ of winning the prize. Tullock (1980) introduced the logit form of the contest success function $p:{ }_{+} \rightarrow[0,1]$ and it has been subsequently adopted in almost all studies of imperfectly discriminating contests (e.g. Corcoran, 1984, Hillman and Samet, 1987, Cleeton, 1989, Perez-Castrillo and Verdier, 1992, Clark and Riis, 1998, Szymanski and Valletti, 2002, Szymanski, 2003). Skaperdas (1996) and Clark and Riis (1998a) offered intuitive axiomatizations of the logit contest success function. $r>0$ is the discriminating power of the contest success function and when $r \rightarrow+\infty$ the contest becomes perfectly discriminating like an all-pay auction (e.g. Krishna and Morgan, 1997, Clark and Riis, 1998b). Assuming an individual's risk neutrality, each contestant maximizes the net expected value of his or her contributed effort (1). 


$$
e_{i}=\underset{e_{i} \geq 0}{\arg \max }\left\{\frac{e_{i}^{r}}{\sum_{j=1}^{n} e_{j}^{r}} V-e_{i}\right\}, i \in[1, n]
$$

Equation (1) coincides with equation (1) in Cleeton (1989), equation (2) in PerezCastrillo and Verdier (1992) and equations (2)-(3) in Szymanski (2003). The complete solution for the Cournot-Nash equilibria of problem (1) is presented in equation (2), which coincides with proposition 4 in Perez-Castrillo and Verdier (1992). The proof is presented in appendix 3 of Perez-Castrillo and Verdier (1992).

$$
\begin{aligned}
\text { a) } e_{i} & =r V \frac{n-1}{n^{2}}, \quad i \in[1, n], \quad r \leq \frac{n}{n-1} \\
\text { b) } e_{i} & =r V \frac{m-1}{m^{2}}, \quad i \in[1, m], \quad \frac{m+1}{m} \leq r \leq \frac{m}{m-1}, m \in[2, n-1] \\
& e_{i}=0, \quad i \in[m+1, n],
\end{aligned}
$$

It follows from equation (2) that the Tullock (1980) contest has the symmetric Nash equilibrium when $r \leq n /(n-1)$, and the asymmetric Nash equilibrium when $n /(n-1) \leq r \leq 2(n \neq 2)$. A natural question arises: what is an equilibrium in the Tullock (1980) contest when $r>2$, i.e. when there is no pure strategy Nash equilibrium? Hillman and Samet (1987) and Baye et al. (1994) derived the mixed strategy Nash equilibrium solution. However, Tullock (1987) questioned the relevance of mixed strategies as a solution concept for the imperfectly discriminating contests where the strategy space is continuous. Perez-Castrillo and Verdier (1992, pp. 344-345) derived the Stackelberg equilibrium (3) when one of the contestants has the superior advantage of a first move.

$$
\begin{gathered}
e_{1}^{S T}=V(r-1)^{1-1 / r} / r, \\
e_{i}=0, \quad i \in[2, n]
\end{gathered}
$$


It follows from equation (3) that the Stackelberg equilibrium exists when $r \geq 1$ (e.g. Perez-Castrillo and Verdier, 1992, p. 345). Specifically, the Stackelberg equilibrium (3) exists even when the pure strategy Nash equilibrium (2) does not exist $(r>2)$. When $r=2$, the effort level of the Stackelberg leader (3) attains its minimum $V / 2$ and coincides with the effort level in the Nash equilibrium (2). When $r=2$, at most two players can participate in the Nash equilibrium, each contributing effort $V / 2$ that yields the expected value of zero. Thus, in the Tullock (1980) contest the definitions of the Nash and Stackelberg equilibrium coincide when $r=2$. The result is remarkable because the Nash equilibrium continuously transforms into the Stackelberg equilibrium when the contest becomes sufficiently discriminating ( $r$ passes the benchmark value of 2). Additionally, it extends the tendency of the Nash equilibrium to transform from the symmetric to the asymmetric equilibrium by decreasing the number of active contestants when the contest becomes relatively discriminating ( $r$ passes the benchmark value of 1). Cleeton (1989, pp. 9-10) and Perez-Castrillo and Verdier (1992, pp. 343-344) discussed the endogenous entry-exit in the Tullock (1980) contest.

Let us consider in detail the Tullock (1980) contest when $r>2$. By observing his best response function (e.g. Perez-Castrillo and Verdier, 1992, pp. 337-339) a contestant realizes that it is inevitable to have only one active contestant in equilibrium. In other words, at most one contestant may contribute positive effort otherwise there is no stable equilibrium. There is, of course, the natural indeterminacy of the identity of this active contestant since all contestants are ex ante identical. Although it is an important issue on its own, the economic models (and this paper is no exception) typically assume that the coordination problem is solved.

Figure 1 plots the best response function of the active contestant $\left(e_{1}\right)$ against all possible effort levels of another contestant $\left(e_{2}\right)$ and vice versa. The two best response functions 
do not intersect, i.e. the Cournot-Nash equilibrium does not exist. Consider the situation when $e_{2}=0$, i.e. the second contestant has no incentive for active participation, which is the only possible scenario compatible with a stable equilibrium. The first contestant may then set an infinitely small effort $e_{1} \rightarrow 0_{+}$that maximizes his instantaneous expected value (1). However, it leads to the unstable melioration equilibrium (e.g. Herrnstein, 1991, Herrnstein and Prelec, 1991). The second contestant then obtains an incentive for active participation and the positive expected value for the first contestant gets eroded. Alternatively, the first contestant may set the effort (3), which is just sufficient to keep the second contestant away from participating.

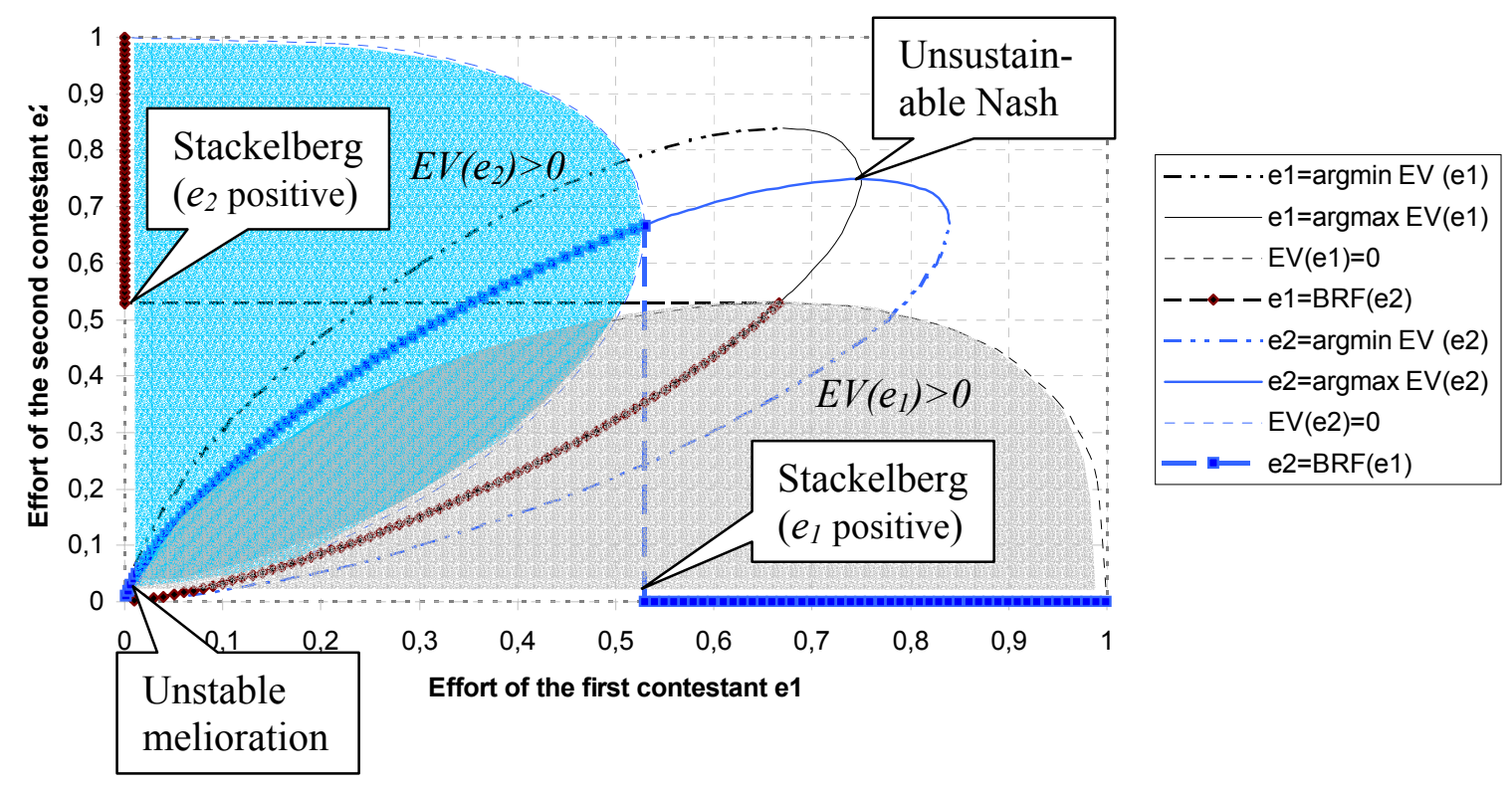

Figure 1 Best response functions of two contestants in a Tullock (1980) contest when $r=3$

The Stackelberg equilibrium (3) arises endogenously in the Tullock (1980) contest when $r>2$, i.e. when there is no room for two active participants. The assumption that the contestants are asymmetric (e.g. one of them has the first move advantage) is not necessary. To avoid the unstable melioration equilibrium it is only necessary that each contestant has a (common) knowledge that others behave exactly as he does. Huck et al. (2002) recently 
provided experimental evidence that the Stackelberg equilibrium arises endogenously in the symmetric set-up. Further discussion of the endogenous Stackelberg equilibrium can be found in van Damme and Hurkens (1999).

Equation (2) and equation (3), when $r>2$, completely characterize the structure of equilibria in the Tullock (1980) contest with the single prize. When two or more contestants actively participate in the Tullock (1980) contest, they contribute identical effort by best responding to each other. When only one contestant actively participates in the contest, he does not best respond to the other (passive) contestants but behaves strategically as the Stackelberg leader.

Notice, that for a given $r$ the aggregate effort $\sum_{i=1}^{n} e_{i}$ and the average effort $\frac{1}{n} \sum_{i=1}^{n} e_{i}$ reach their maximum in the symmetric Nash equilibrium and their minimum in the asymmetric equilibria. The maximum individual effort $\max _{i \in[1, n]} e_{i}$ exhibits the opposite pattern. If the aggregate (average) effort is the objective of the contests' organizers then the asymmetric equilibria are undesirable. The same holds true if the objective of the contests' organizers is a better competitive balance (a closer contest e.g. Szymanski, 2003, p.1143). The standard deviation of the contestants' effort is minimum (zero) only in the symmetric Nash equilibrium. The best policy to avoid the asymmetric equilibria in the single prize contest is to limit the number of contestants. However, when $r>2$ the asymmetric equilibrium is unavoidable due to the exogenous nature of the discriminating power $r$. This problem can be cured with the introduction of multiple prizes as shown in section 3.

Finally, it is interesting to notice that in the Stackelberg equilibrium $\lim _{r \rightarrow+\infty} e_{1}^{S T}=V$. When the contest becomes increasingly discriminating (less noisy) one contestant contributes 
an effort $e_{1}^{S T}$ close to the prize value $V$ and no other contestants participate. The equilibrium effort $e_{1}^{S T}$ cannot fall too short of $V$. Otherwise a passive contestant has the incentive to contribute an effort slightly above $e_{1}^{S T}$. Such higher effort then wins the prize almost with certainty (the contest is almost perfectly discriminating) and it has the positive expected value. Since $\lim _{r \rightarrow+\infty} e_{1}^{S T}=V$, the possibility of observing $\sum_{i=1}^{n} e_{i}>V$ ("over dissipation of rents" conjectured by Tullock, 1980) does not occur in the Stackelberg equilibrium.

\section{Tullock (1980) contest with two prizes}

Consider the contest described in section 2 with two prizes $V_{1}=\alpha V$ and $V_{2}=(1-\alpha) V, \alpha \in[0.5,1)$ instead of the single prize $V$. Each contestant contributes an effort $e_{i} \geq 0, i \in[1, n]$, and has the probability $p_{1}\left(e_{i}\right)=e_{i}^{r} / \sum_{j=1}^{n} e_{j}^{r}$ of winning the first prize and the probability $p_{2}\left(e_{i}\right)=p_{1}\left(e_{i}\right) \cdot \sum_{\substack{k=1 \\ k \neq i}}^{n} e_{k}^{r} / \sum_{\substack{l=1 \\ l \neq k}}^{n} e_{l}^{r}$ of winning the second prize. Given the logit contest success function $p_{1}($.$) , the probability of winning the second prize p_{2}($.$) is "simply the$ probability of winning a contest with $n-1$ contestants conditional on not having won the first prize" (e.g. Szymanski and Valletti, 2002). The optimization problem of each contestant is given by equation (4). Equation (4) is equivalent to equations (5)-(6) in Szymanski (2003).

$$
e_{i}=\underset{e_{i} \geq 0}{\arg \max }\left\{\frac{e_{i}^{r}}{\sum_{j=1}^{n} e_{j}^{r}} V\left(\alpha+(1-\alpha) \sum_{\substack{k=1 \\ k \neq i}}^{n} \frac{e_{k}^{r}}{\substack{l=1 \\ l \neq k}} e_{l}^{r}\right)-e_{i}\right\}, i \in[1, n]
$$




\subsection{The structure of equilibria}

When three or more contestants actively participate in the Tullock (1980) contest with two prizes, they best respond to each other and contribute identical (positive) effort. The remaining (if any) contestants contribute zero effort. When only two contestants actively participate in the contest, they do not necessarily best respond to each other because they may need to behave strategically. This case is considered in detail later on. A straightforward maximization of equation (4) yields the equilibrium level of effort (5).

$$
\begin{gathered}
e_{i}=\frac{r V}{m}\left(\frac{m-1}{m}-\frac{1-\alpha}{m-1}\right), i \in[1, m] \\
e_{i}=0, i \in[m+1, n]
\end{gathered}
$$

where $m \in[3, n]$ is the number of active contestants in equilibrium. When $m=n$ equation (5) coincides with formula (7) in Szymanski (2003, p. 1143). The number $m$ of active participating contestants in equilibrium is determined from the following constraint. An active contestant cannot contribute the effort (5) that yields the negative expected value (the expected value of zero effort is always zero). This results in constraint (6).

$$
r \leq \frac{1}{1-\frac{1}{m}-\frac{1-\alpha}{m-1}}
$$

The number of active contestants is the highest number $m \in[3, n]$ that satisfies constraint (6).

It follows from (5)-(6) that the Tullock (1980) contest with two prizes has a symmetric Nash equilibrium when $r \leq \frac{n(n-1)}{(n-1)^{2}-n(1-\alpha)}$. It is noteworthy that the upper bound on the discriminating power $r$ of the contest success function compatible with the existence of the symmetric Nash equilibrium decreases in $\alpha$. In other words, when more of a total prize fund $V$ is shifted to the second prize, the symmetric Nash equilibrium is compatible with a wider range 
of the contest success functions. Equations (5)-(6) also imply that when $\frac{n(n-1)}{(n-1)^{2}-n(1-\alpha)} \leq r \leq \frac{6}{1+3 \alpha}$ the Tullock (1980) contest with two prizes has an asymmetric Nash equilibrium with at least three active contestants. It follows from constraint (6) that the number $m$ of active contestants in an asymmetric Nash equilibrium increases when more of a total prize fund is shifted to the second prize.

It follows from (6) that when $r>6 /(1+3 \alpha)$, at most two contestants may contribute positive effort in equilibrium. The minimum number of active contestants in the Tullock (1980) contest with two prizes is two. Whatever the effort of one active contestant is, at least one more contestant always has the incentive for active participation if the second prize exists. When only two contestants actively participate in the Tullock (1980) contest with two prizes, three different types of equilibria exist. First, two active contestants may contribute identical effort $e_{1,2}=0.25 r V(2 \alpha-1)$. This is the asymmetric Nash equilibrium (5) for the case $m=2 .{ }^{1}$ This equilibrium is sustainable when two active contestants have the incentive for active participation but there is no room for three active contestants in equilibrium. Formally, constraint (6) holds for $m=2$ but does not hold for $m=3$ i.e. $6 /(1+3 \alpha) \leq r \leq 1 /(\alpha-0.5)$. Additionally, $n-2$ passive contestants have no incentive for active participation given the equilibrium effort of two active contestants. Formally, the equilibrium effort $e_{1,2}=0.25 r V(2 \alpha-1)$ must satisfy the constraint (7), which approximately can be written as the constraint $r \geq 4 /(6 \alpha-3) .^{2}$

\footnotetext{
${ }^{1}$ This equilibrium also coincides with the asymmetric Nash equilibrium (2) for the case $m=2$ when the single prize is equal to the difference between the first and the second prize in the two-prize contest: $(2 \alpha-1) V$.

${ }^{2}$ The exact constraint is $r(2 \alpha-1)(f+1)(f+2) \geq 4 f^{1-1 / r}(2+\alpha(f-1))$, where $f$ is a non-negative solution of the cubic equation $f^{3}+2 f^{2}(1-2 r+(r+1) / \alpha)-f(4 r+1-6 / \alpha)+2(r-1)(1-2 / \alpha)=0$.
} 


$$
\frac{e^{r}}{e^{r}+e_{1}^{r}+e_{2}^{r}} V\left(\alpha+(1-\alpha)\left(\frac{e_{1}^{r}}{e^{r}+e_{2}^{r}}+\frac{e_{2}^{r}}{e^{r}+e_{1}^{r}}\right)\right)-e \leq 0, \forall e>0
$$

Intuitively, the two-player asymmetric Nash equilibrium is the equilibrium when two active contestants know that they obtain at least the second prize $(1-\alpha) V$ with certainty. Such confidence arises because the contest is sufficiently discriminating. If three contestants attempt to participate they all expect the negative value in equilibrium. Each of two active contestants then chooses the effort that maximizes his chance of winning the difference between the first and the second prize: $(2 \alpha-1) V$.

The second type of equilibrium is a mixture of the Nash and Stackelberg equilibrium. It occurs when $6 /(1+3 \alpha) \leq r \leq 1 /(\alpha-0.5)$ but $e_{1,2}=0.25 r V(2 \alpha-1)$ does not satisfy constraint (7). For example, this case happens when a total prize fund is more or less equally divided between two prizes $(\alpha \approx 0.5)$. Each of two active contestants then has an incentive to contribute a very low effort (two prizes are more or less the same and there is no sense in strong competition). However, constraint (7) warrants each of the two active participants from reducing his or her effort too much. Otherwise, a third contestant becomes motivated in participation and the two incumbents cannot remain assured that they receive at least the second prize with certainty. Thus, in equilibrium one active contestant chooses the minimum effort $e_{1}$ so that the constraint (7) holds at most as equality (given an effort $e_{2}$ of the second contestant). He behaves strategically as if the Stackelberg leader is keeping other contestants away from participation. The second active contestant chooses his effort $e_{2}$ that maximizes the expected value (4) given that the first active contestant contributes $e_{1}$ and the remaining $n-2$ contestants contribute zero effort. He behaves as the classical Cournot-Nash best responder. 
Formally, equation (8) describes the equilibrium behavior of two active contestants in this mixed Nash-Stackelberg equilibrium.

$$
\begin{gathered}
e_{1}=\underset{e_{1} \geq 0}{\arg \min }\left\{\frac{e^{r}}{e^{r}+e_{1}^{r}+e_{2}^{r}} V\left(\alpha+(1-\alpha)\left(\frac{e_{1}^{r}}{e^{r}+e_{2}^{r}}+\frac{e_{2}^{r}}{e^{r}+e_{1}^{r}}\right)\right)-e \leq 0, \forall e>0\right\} \\
e_{2}=\underset{e_{2} \geq 0}{\arg \max }\left\{\frac{e_{2}^{r}}{e_{1}^{r}+e_{2}^{r}}(2 \alpha-1) V+(1-\alpha) V-e_{2}\right\}
\end{gathered}
$$

The third type of equilibrium is an analogue of the Stackelberg equilibrium in the contest with two prizes. It occurs when $r>1 /(\alpha-0.5)$. Such a contest is almost perfectly discriminating. Two active contestants cannot end up in the asymmetric Nash equilibrium (5) for the case $m=2$. In the Nash equilibrium each active contestant has to contribute such a high effort that this effort has the negative expected value. Intuitively, if one contestant contributes low effort, the second contestant has the incentive to contribute a slightly higher effort. The second contestant then wins the first prize almost with certainty (the contest is almost perfectly discriminating) and his or her effort has the expected positive value. However, the first contestant then has the incentive to increase his or her effort and so forth. This situation is similar to the single prize contest when $r>2$.

Two active contestants cannot end up in a stationary equilibrium by best responding to each other's effort. Therefore, they contribute efforts $e_{1}$ and $e_{2}$ that are just sufficient to give the remaining $n-2$ passive contestants no incentive for active participation. The first active contestant submits the effort $e_{1}=\alpha V(r-1)^{1-1 / r} / r$. It follows from formula (3) that such an effort is just sufficient to eliminate any incentive for active participation (for the remaining $n-1$ contestants) arising from the prospect of winning the first prize $\alpha V$. However, there still exists a positive value second prize $(1-\alpha) V$. It gives the incentive for active participation for at 
least one more contestant. Thus, the second active contestant submits the effort $e_{2}=(1-\alpha) V(r-1)^{1-1 / r} / r$. Formula (3) shows that such effort is just sufficient to give the remaining $n-2$ contestants no incentive for active participation stemming from the prospect of winning the second prize $(1-\alpha) V$. When $r \rightarrow \infty$, i.e. when the contest becomes an all-pay auction with 2 prizes, the first contestant submits an effort $e_{1}=\alpha V$ and the second contestant submits an effort $e_{2}=(1-\alpha) V$. Thus, in this Stackelberg equilibrium two active contestants bid the exact values of two prizes and the remaining contestants bid zero. The possibility of “over dissipation of rents" $\sum_{i=1}^{n} e_{i}>V$ does not occur.

Table 1 conveniently summarizes the structure of equilibria in the Tullock (1980) contest with two prizes and $n>2$ contestants. In the special case $n=2$, the equilibrium is $e_{1}=e_{2}=0.25 r V(2 \alpha-1) \quad$ when $r \leq 1 /(\alpha-0.5)$ and $e_{1}=(2 \alpha-1) V(r-1)^{1-1 / r} / r, e_{2}=0$ when $r>1 /(\alpha-0.5)$. When $\alpha=1$, table 1 presents the structure of equilibria in the Tullock (1980) with the single prize (as presented in section 2).

\begin{tabular}{|c|c|}
\hline Equilibrium effort of contestants & Equilibrium conditions \\
\hline$e_{i}=\frac{r V}{n}\left(\frac{n-1}{n}-\frac{1-\alpha}{n-1}\right), i \in[1, n]$ & $r \leq \frac{n(n-1)}{(n-1)^{2}-n(1-\alpha)}$ \\
\hline$e_{i}=\frac{r V}{m}\left(\frac{m-1}{m}-\frac{1-\alpha}{m-1}\right), i \in[1, m]$ & $\frac{1}{1-\frac{1}{m+1}-\frac{1-\alpha}{m}} \leq r \leq \frac{1}{1-\frac{1}{m}-\frac{1-\alpha}{m-1}}, m \in[3, n]$ \\
$e_{i}=0, i \in[m+1, n]$ & $6 /(1+3 \alpha) \leq r \leq 1 /(\alpha-0.5), r \geq 4 /(6 \alpha-3)$ \\
\hline$e_{1}=e_{2}=0.25 r V(2 \alpha-1), e_{i}=0, i \in[3, n]$ & $6 /(1+3 \alpha) \leq r \leq 1 /(\alpha-0.5), r<4 /(6 \alpha-3)$ \\
\hline solution of $(8)$ & $r>1 /(\alpha-0.5)$ \\
\hline$e_{2}=\alpha V(r-1)^{1-1 / r} / r$, & \\
\hline
\end{tabular}

Table 1 The structure of equilibria in the Tullock (1980) contest with two prizes $(n>2)$ 
The intuitive explanation of the equilibrium structure from table 1 is as follows. When the contest is relatively undiscriminating, all contestants actively participate in the contest because there is a possibility to win a prize (almost by chance) while contributing low effort. When the contest becomes sufficiently discriminating, up to $n-2$ contestants may drop out from the competition. The remaining active contestants are expected to contribute such a high effort that it erases any expectations of winning a prize for the passive contestants. However, when a prize fund is more evenly divided, fewer contestants drop out than when a prize fund is largely allocated to the first prize. Even when the contest is sufficiently discriminating, there is a higher chance to win one of two prizes than the single prize. When the contest is almost perfectly discriminating, only two contestants actively participate in equilibrium, which may be the Nash, mixed Nash-Stackelberg or two-player Stackelberg equilibrium.

\subsection{Comparative statics}

The contests' organizers may have three different objectives-to maximize an individual's effort $\left(\max _{i \in[1, n]} e_{i}\right)$, to minimize the standard deviation of the contestants' effort or to maximize the aggregate (average) effort. In other words, the contests' organizers may wish to observe the highest winning effort (the breaking of a world record), a close contest (a competitive balance resulting in an interesting competition) or to maintain the overall quality of the contest (e.g. Szymanski, 2003, p. 1143). Which prize structure suits each of these goals the best?

Suppose that the contests' organizers wish to maximize an individual's effort $\left(\max _{i \in[1, n]} e_{i}\right)$. Table 1 shows that the introduction of the second prize (decrease in $\alpha$ ) unambiguously reduces the highest submitted effort for all possible parameterizations. Thus, the single prize contest is the optimal contest architecture for maximizing an individual's effort. Figure 2 demonstrates 
this conclusion for a contest with 10 participants. Intuitively, when more of a total prize fund is shifted to the second prize, the expected value of winning either the first or the second prize increases. The chances of winning a prize become more favorable for each level of an individual's effort. Thus, active contestants are motivated to decrease their effort in equilibrium.

Additionally, there is an indirect effect. When more of a total prize fund is shifted to the second prize, the number of active contestants either increases or remains the same. This conclusion follows from the equilibrium conditions in table 1 - when $\alpha$ decreases, the number $m$ of active contestants has to increase (to sustain the same discriminating power $r$ ). If more contestants actively participate in the contest, the active contestants are additionally motivated to reduce their effort (e.g. Cleeton, 1989, pp. 9-10; Szymanski, 2003, p.1142).

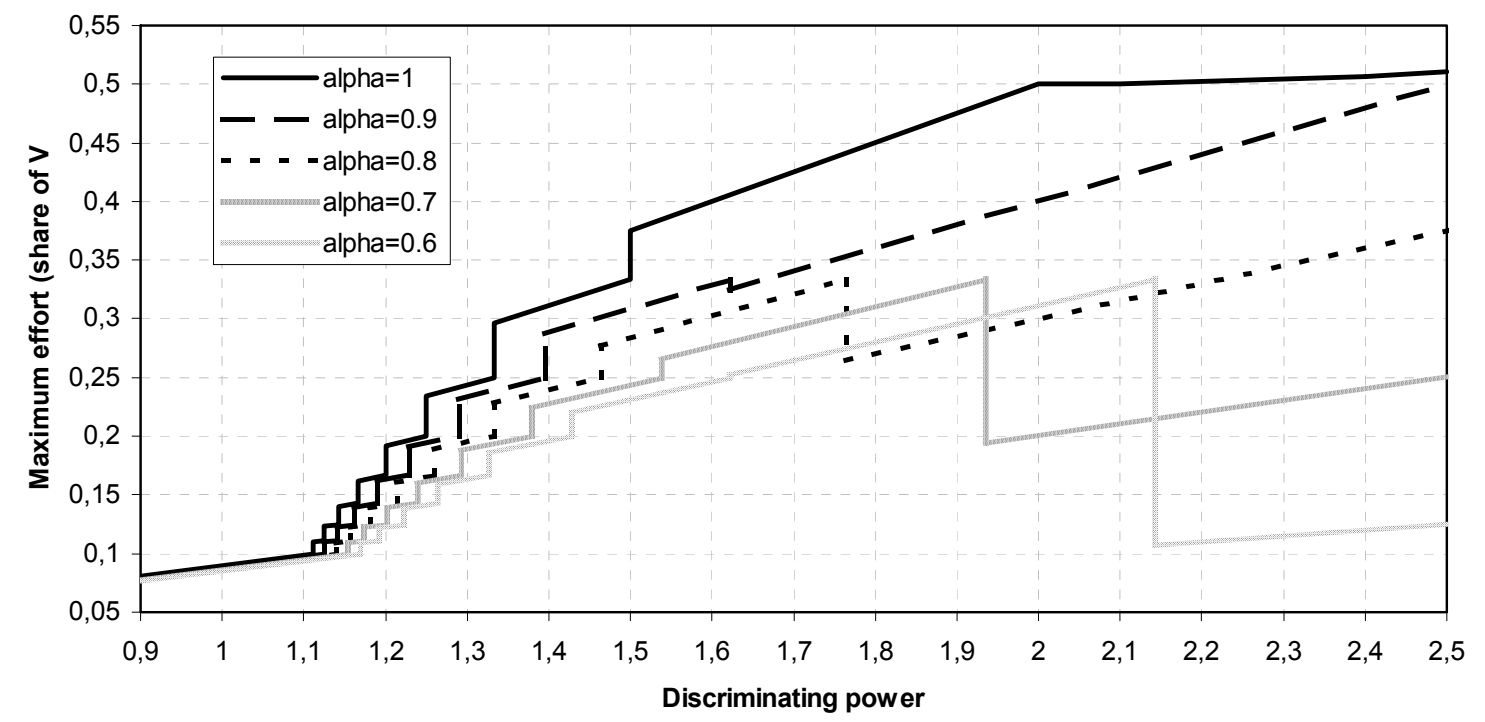

Figure 2 Maximum individual effort in a contest with 2 prizes and 10 contestants

Suppose that the contests' organizers wish to maintain a competitive balance (close contest). Their objective then is to minimize the standard deviation of the contestants' effort. In the Cournot-Nash equilibria when $m$ active contestants contribute identical effort $e_{m}$, the 
standard deviation of the contestants' effort is $e_{m} \sqrt{m(1-m / n)}$. When more of a total prize fund is shifted to the second prize, the effort $e_{m}$ of active contestants unambiguously decreases (table 1 and figure 2). Thus, the gap between the efforts of active $\left(e_{m}\right)$ and passive (zero) contestants is narrowed and, ceteres paribus, the standard deviation of effort decreases.

The introduction of the second prize may also increase the number $m$ of active contestants. When active contestants are in relative majority $(m \geq n / 2)$, the increase in their number unambiguously decreases the standard deviation of effort: $e_{m} \sqrt{m(1-m / n)}$. Otherwise, the increase in the number of active contestants can widen the dispersion of effort in the contest. Figure 3 demonstrates this conclusion for the contest with 10 participants. When five or more contestants actively participate in the single prize contest $(r \leq 1.25)$, the introduction of the second prize always reduces the standard deviation of the contestant's effort. When less than five contestants actively participate in the contest $(r>1.25)$, the introduction of the second prize can increase the standard deviation of effort. Thus, when the objective of the contests' organizers is a competitive balance, the introduction of the second prize is always desirable when the majority (but not all) contestants actively participate in the single prize contest. 


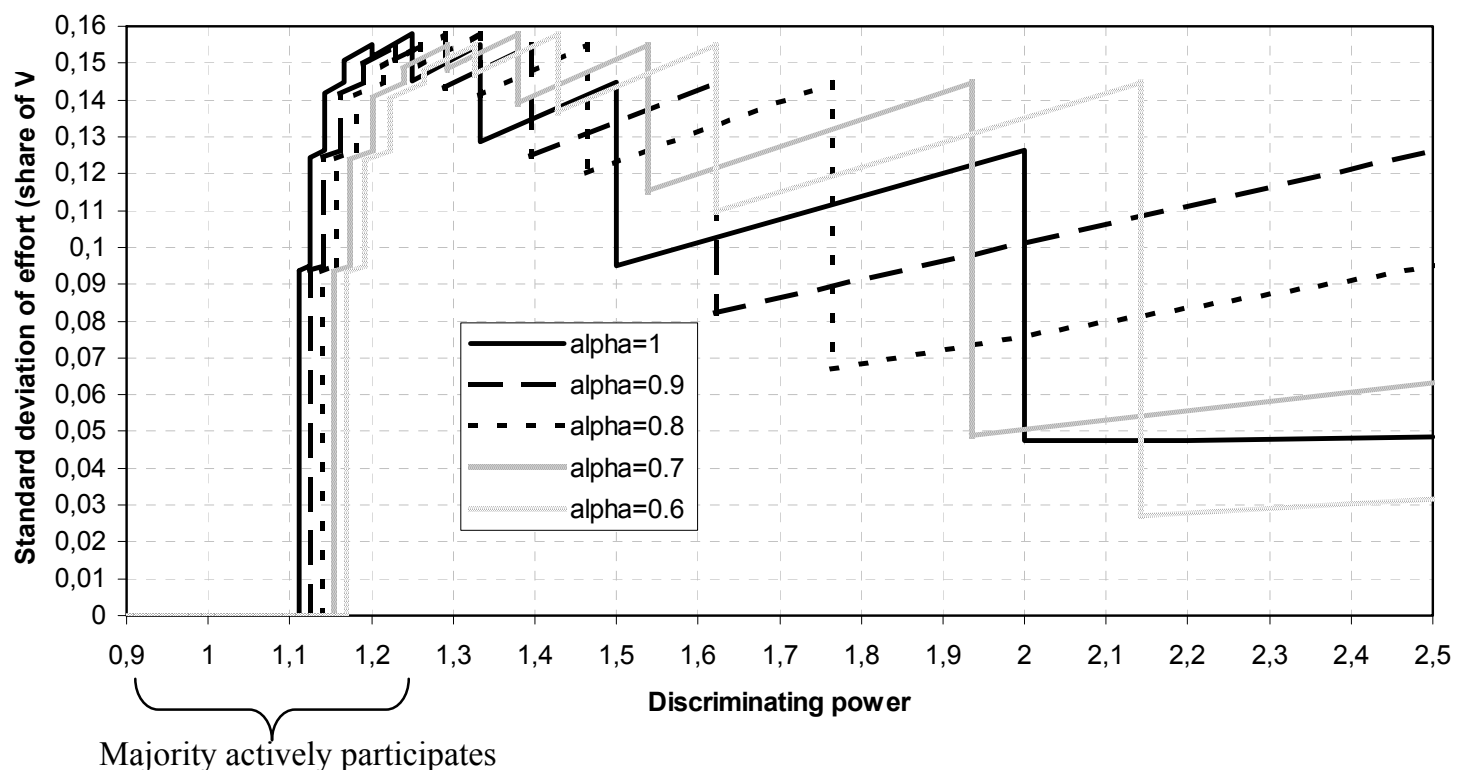

Figure 3 Standard deviation of effort in the contest with 2 prizes and 10 contestants

Finally, suppose that the contests' organizers wish to maintain the overall quality of the contest. Their objective then is to maximize the aggregate $\sum_{i=1}^{n} e_{i}$ or the average $\frac{1}{n} \sum_{i=1}^{n} e_{i}$ effort in the contest. When more of a total prize fund is shifted to the second prize, it has a twofold effect on the aggregate (average) effort contributed in the contest. On the one hand, the effort of active contestants unambiguously decreases (table 1 and figure 2). On the other hand, the number of active contestants may increase. Thus, the introduction of the second prize has an ambiguous effect on the aggregate (average) effort in the asymmetric equilibria. Figure 4 demonstrates this conclusion for the contest with 10 participants. When the symmetric Cournot-Nash equilibrium is sustainable in the single prize contest $(r<10 / 9)$, the introduction of the second prize always reduces the aggregate (average) effort. This result is well documented in the literature (e.g. Clark and Riis, 1998; Szymanski, 2003, p.1142). However, in the asymmetric equilibria the introduction of the second prize may increase the aggregate (average) effort when the number of active contestants increases $($ e.g. $n=10, r=1.6)$. 


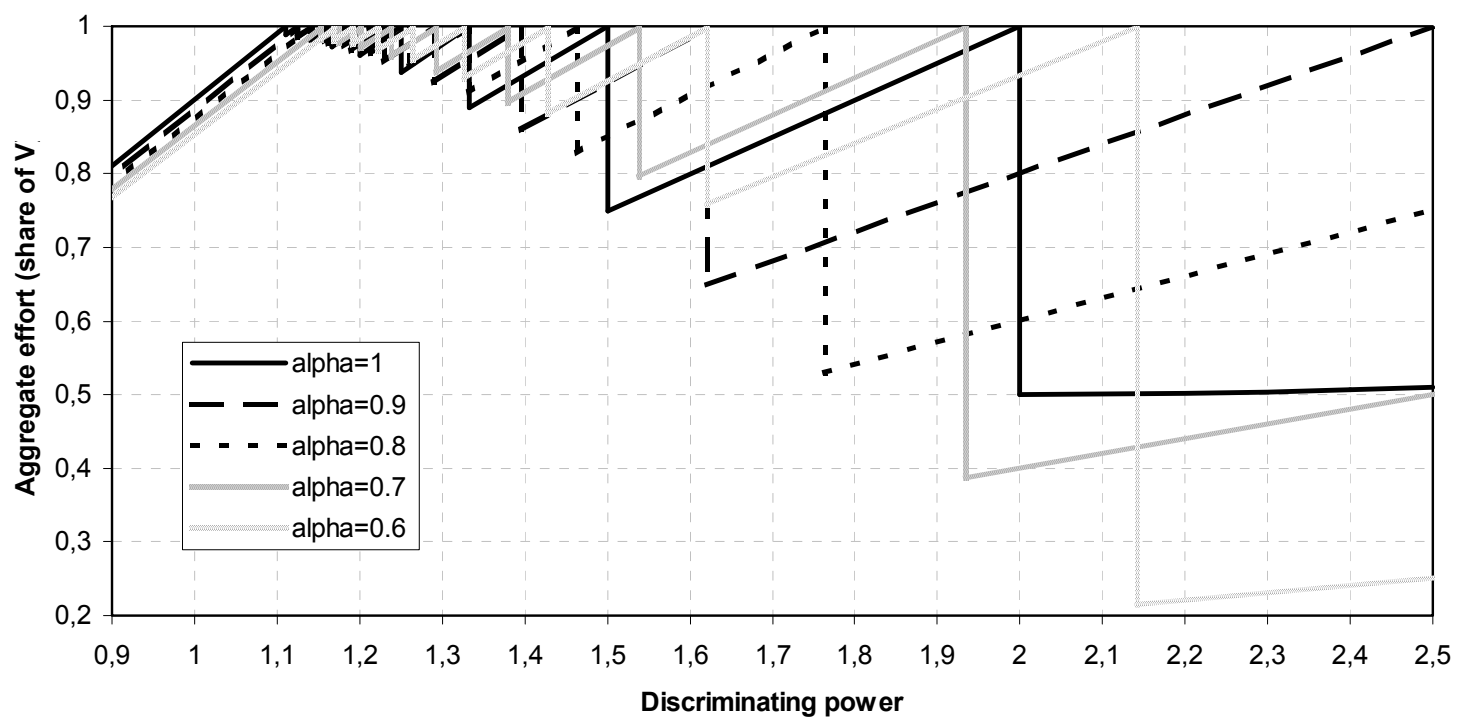

Figure 4 Aggregate effort in the contest with 2 prizes and 10 contestants

The aggregate effort cannot exceed the total prize fund $V$ (figure 4). It can fall short of $V$ when the contestants end up either in the symmetric Nash equilibrium (the contest is poorly discriminating) or in the asymmetric equilibria with few active contestants (the contest is very discriminating). When the contests' organizers observe low aggregate effort with $100 \%$ participation, the problem is the poor discriminating power of the contest. Shifting more of a total prize fund away from the first prize cannot cure such problem (on the contrary it only aggravates the problem). However, when the contests' organizers observe low aggregate effort with many passive contestants, the problem is the extreme discriminating power of the contest. In this case, if the discriminating power of the contest success function is known, the contests' organizers can calculate the optimal size of the second prize that maximizes the aggregate effort. When the discriminating power of the contest success function is unobservable, the contests' organizers may increase the number of active contestants by shifting more of a total prize fund away from the first prize. When only a few contestants (ideally one contestant) are endogenously passive, the aggregate effort is maximized. Generally, it may not reach its 
absolute maximum $V$ but it cannot fall substantially short of $V$. When all but one contestant actively participate in the contest, even a small deviation of the aggregate effort from $V$ is sufficient to trigger the endogenous entry and exit (e.g. figure 4 when $1.1 \leq r \leq 1.2$ ), which is observable for the contests' organizers. Thus, in order to maximize the aggregate effort, the contests' organizers should offer enough prizes to leave only a few (ideally one) passive contestants in the asymmetric equilibria. 


\section{Conclusion}

This paper explores the asymmetric equilibria in a symmetric imperfectly discriminating contest with the logit contest success function and linear cost of effort, known in the literature as the Tullock (1980) contest. Such contests are typical in high-level sport. The asymmetric equilibria arise in the symmetric setup when the contest is sufficiently discriminating and some contestants drop out from competition. This creates an interesting coordination problem (indeterminacy of the ex ante identical individuals who drop out) and a commitment problem in the endogenous Stackelberg equilibrium. These questions are left for further (perhaps experimental) research.

The single prize is not necessarily the optimal prize structure when the contestants are identical in effort ability. Multiple prizes may be desirable when the contests' organizers wish to maintain a competitive balance or the overall quality of the contest. The introduction of multiple prizes always reduces the standard deviation of the contestants' effort when the majority (but not all) of the contestants actively participate in the contest. The introduction of multiple prizes may also increase the aggregate (average) effort contributed in the contest. On the one hand, multiple prizes always reduce the effort of active contestants. On the other hand, multiple prizes may increase the number of active contestants in the asymmetric equilibria. Thus, the aggregate (average) effort always decreases in the symmetric Cournot-Nash equilibrium but it may increase in the asymmetric equilibria with the introduction of multiple prizes.

Interestingly, in Ancient Greece the Olympics had only one official prize (an olive branch), which is the optimal prize structure for maximizing an individual's effort. In contrast, the modern day Olympics have three official prizes (gold, silver and bronze medals). 
Apparently, during the last 2500 years the preferences of the general public have changed from an individual record-breaking performance in favor of interesting competition and/or a high overall quality of the contest.

If the discriminating power of the logit contest success function is known, the contests' organizers can design the optimal prize structure to meet their objectives. Further extension of this work could be to design the optimal prize structure when the discriminating power is unknown. This would be a quest for the probabilistically optimal prize structure that suits the objectives of the contests' organizers within the widest range of the contest success functions. The single prize contest may be still probabilistically optimal though it is not necessarily optimal for a specific parameterization. It would be intriguing to explore under which conditions three prizes (commonly observed in the real-life contests) are desirable.

Imperfectly discriminating contests can be viewed in their relation to the all-pay auctions. When the contest becomes progressively discriminating, first the symmetric and then the asymmetric Cournot-Nash equilibria (in pure strategies) become unsustainable. Two alternative equilibrium solution concepts exist for the highly discriminating contests and allpay auctions. The first is the solution in mixed strategies. The second (advocated in this paper) is the solution in pure strategies for the endogenous mixed Nash-Stackelberg or pure Stackelberg equilibrium. In the symmetric (common value) all-pay auction this solution concept yields the equilibrium where $k$ participants bid exactly the value of one of $k$ prizes and the remaining participants bid zero. This equilibrium contrasts with the solution in mixed strategies (e.g. Clark and Riis, 1998b, Moldovanu and Sela, 2001). The interpretation of such duality may be that the solution in mixed strategies is the mathematical method to model the natural indeterminacy of the asymmetric equilibrium when all participants are ex ante identical. 


\section{References}

Baye M., Kovenock D. and de Vries C. (1994) "The Solution to the Tullock RentSeeking Game When R > 2: Mixed-Strategy Equilibria and Mean Dissipation Rates," Public Choice, 81, pp. 363-380.

Clark, D. and Riis, Ch. (1998) "Influence and the discretionary allocation of several prizes" European Journal of Political Economy 14, 605-625

Clark, D. and Riis, Ch. (1998a) "On the design of symmetric rent-seeking contests with several winners" Public Choice

Clark, D. and Riis, Ch. (1998b) "Competition over more than one prize" American Economic Review 88, 276-289

Cleeton, D. (1989) "Equilibrium conditions for efficient rent seeking: the Nash-Cournot solution" Quarterly Review of Economics and Business 29, 6-14

Corcoran, W. (1984) "Long-run equilibrium and total expenditures in rent-seeking" Public Choice 43, 89-94

Cornes, R. and Hartley, R. (2003) "Loss Aversion and the Tullock Paradox" Keele Economics Research Papers No. 2003/06

Dixit, A. (1987) "Strategic behavior in contests" American Economic Review 77, 891-898

Herrnstein, R. (1991) "Learning and Adaptive Economic Behavior Experiments on Stable Suboptimality in Individual Behavior" American Economic Review 81, 360-364

Herrnstein, R and Prelec, D. (1991) "Melioration: A Theory of Distributed Choice" The Journal of Economic Perspectives 5, 137-156

Hillman, A. and Samet, D. (1987) "Dissipation of contestable rents by small numbers of contenders" Public Choice 54, 63-82

Huck S., Mueller W. and Normann, H. (2002) "To commit or not to commit: endogenous timing in the experimental duopoly markets" Games and Economic Behaviour, 38, 240-264

Krishna V. and Morgan J. (1997) "An analysis of the war of attrition and the all-pay auction" Journal of Economic Theory, 72, 2, 343-62

Moldovanu B. and Sela A. (2001) "The optimal Allocation of Prizes in Contests" American Economic Review, 91, 3, 542-558

Moldovanu B. and Sela A. (2002) “Contest Architecture” SFB 504 discussion paper No. 02-06 
Neale W. (1964) "The Peculiar Economics of Professional Sport" Quarterly Journal of Economics, 78, 1-14.

Nitzan, S. (1994) "Modelling Rent-Seeking Contests," European Journal of Political Economy $10,41-60$

Perez-Castrillo, J., Verdier, T. (1992) “A general analysis of rentseeking games” Public Choice $73,335-50$

Skaperdas S. (1996) “Contest Success Functions”, Economic Theory, 7, 283-90

Szymanski S. (2003) "The Economic Design of Sporting Contests" Journal of Economic Literature, 41, 1137-1187

Szymanski S. and Valletti T. (2002) "First and second prizes in imperfectly discriminating contests" working paper

Tullock, G. (1980) "Efficient Rent Seeking" in J. Buchanan R Tollison and G. Tullock, eds. Toward a Theory of Rent Seeking Society. Texas A\&M University Press, 97-112

Tullock, G. (1987) “Another part of the swamp” Public Choice 54, 83-84

van Damme, E. and Hurkens, S. (1999) "Endogenous Stackelberg leadership" Games and Economic Behaviour, 28, 105-129 